\title{
Wave like signatures in aerosol optical depth and associated radiative impacts over the central Himalayan region
}

\author{
K.K.Shukla ${ }^{1,2}$, D.V.Phanikumar ${ }^{1,3}$, K. Niranjan Kumar $^{3}$, Kishore Reddy ${ }^{4}$, V. R. Kotamarthi ${ }^{5}$, Rob K \\ Newsom $^{6}$ and Taha B.M.J Ouarda ${ }^{3,7}$ \\ ${ }^{1}$ Aryabhatta Research Institute of observational sciences, Nainital, India \\ ${ }^{2}$ Pt. Ravishankar Shukla University, Raipur, Chhattisgarh, India \\ ${ }^{3}$ Institute Center for Water and Environment, Masdar Institute of Science and Technology, Abu Dhabi, \\ United Arab Emirates \\ ${ }^{4}$ Department of Physics, Yogi Vemana University, Kadapa, India \\ ${ }^{5}$ Argonne National Laboratory, Argonne, Illinois, USA \\ ${ }^{6}$ Pacific Northwest National Laboratory, Richland, Washington, USA \\ ${ }^{7}$ INRS-ETE, Quebec (Qc), Canada
}

Corresponding author: D V Phanikumar (astrophani@gmail.com ; phani@aries.res.in ) 
Key words: Doppler Lidar; GVAX; Aerosol optical depth; Aerosol radiative forcing 


\section{Introduction}

The foothill region of the Himalaya in northern India acts as a barrier for aerosol transport from the Ganges Valley region. The Himalayan region is known as the third pole and is home to a number of glaciers that sustain rivers, which flow into South Asia (http://www.icimod.org/?q=3487). Moreover, the Himalayan region is the potential receptor of the aerosols from the Indian/Pakistan source region due to synoptic scale transport (Kotamarthi, 2010; Duchi et al., 2014). Mountain breezes also play an important role in transporting pollutants up to higher altitude in the Himalayan region (Komppula et al., 2009).

Earlier, Sagar et al. (2004) showed from their observations that Manora peak $\left(29.4^{0} \mathrm{~N}\right.$; $79.2^{0} \mathrm{E} ; 1958 \mathrm{~m}$ amsl) can be considered as a free tropospheric site due to high elevation and far away from anthropogenic activity. However, in recent years the Indo-Gangetic Plain (IGP) region experiences an increase in aerosol loading as evident from different ground-based and space-borne measurements (Jethva et al., 2005). In the past, several reports from the high altitude site showed that the high aerosol concentration observed during daytime and attributed to upslope wind, valley breezes and regional/long range transport (Komppula et al., 2009; Gobbi et al., 2010). It is also argued that the atmospheric boundary layer (ABL) in particular plays a key role in transporting the aerosols from the surface to the free troposphere during the daytime upslope wind due to convection (Stull, 1989; Gibert et al., 2011; Shukla et al., 2014). The diurnal variations in trace species over Nainital are shown to be controlled by upslope-downslope winds, photochemistry and boundary layer dynamics (Ojha et al., 2012; Sarangi et al., 2014).

During GVAX campaign, an increase in the absorption is observed due to coarse mode aerosol particles over the Himalayan region and its contribution is $\sim 30 \%$ greater in comparison to the fine mode aerosol particles. Also, the contribution of coarse mode aerosols in the aerosol 
radiative forcing over the Himalayan region is found to show $~ 50 \%$ increase in the regional aerosol radiative forcing (Manoharan et al., 2014). Dumka et al. (2015) showed the diurnal variation of aerosols scattering and absorption coefficient over the Manora peak, Nainital and attributed the dominance of aerosols due to the transport from the Ganges basin and west Asia and also ABL dynamics during noon hours. Hence, it is important to understand the regional impact of increased aerosol pollution which mainly depends on the amount of aerosols ventilated/entrained from $\mathrm{ABL}$ into the layers of the troposphere above. Nevertheless, observational support of atmospheric dynamics to these aerosol observations based analysis is still lacking.

On the other hand, Dumka et al. (2006) observed higher aerosol optical depth (AOD) during afternoon in comparison to forenoon (defined as forenoon-afternoon asymmetry) and hypothesized that the growth of ABL brings the polluted air from the nearby valley region to the site. This study also emphasized the importance of daytime AOD variation and associated dynamics at an elevated site in the central Himalayan region.

The incidence of the gravity waves in the stably-stratified atmosphere is the dynamical phenomenon on all meteorological scales in the atmosphere (Nappo, 2002; Manoj and Devara 2011; Niranjan Kumar et al., 2014). Several source mechanisms are proposed in the past for the generation of short-period gravity waves in the atmosphere, for example, flow over the topography (Niranjan Kumar et al. 2012); wind-shear (Fritts and Alexander, 2003; Ramkumar et al., 2010) and convection (Niranjan Kumar et al., 2014). Gravity waves can occur from the surface to the upper atmosphere with periods ranging from minutes (or less) to hours propagating both vertically and horizontally and transporting energy and momentum in the atmosphere (Fritts and Alexander, 2003). Few studies in the past focused on influence of short-period and long- 
period modulations in the aerosols and related ABL dynamics (Beegum et al., 2009; Manoj and Devara, 2011; Das et al., 2011; Phanikumar et al., 2014). For instance, Manoj and Devara (2011) showed quasi periodic modulations in Lidar backscatter signal strength during nocturnal boundary layer. Another study by Das et al. (2011) showed that dust storms at distant locations generate short-period gravity waves and can have an impact on middle and upper atmospheric dynamics. Therefore, it is important to understand the influence of short-period modulations keeping in view of the complex topography of the observational site during the ABL evolution.

In the view of the above, Ganges Valley Aerosol Experiment (GVAX) gives an opportunity to address the daytime AOD variation and associated dynamics over the site (Manoharan et al., 2014; Dumka et al., 2014a, b; Dumka et al.,2015). The present study aims to investigate for the first time, the influence of wave like signatures in vertical velocity and AOD data obtained from a ground-based Doppler Lidar and Multi Filter Rotating Shadow band Radiometer (MFRSR) during daytime ABL evolution over the central Himalayan region.

\section{Topography and general meteorology of the observational site}

The first Atmospheric Radiation Measurement (ARM) mobile facility (AMF1) was deployed, as part of the Indo-US collaborative project GVAX, over a high altitude site Manora Peak, Nainital, situated in the central Himalayan region for the period June 2011 - March 2012. The topography of the adjoining region is highly complex and the detailed description about the site can be found in Kumar et al., (2010). The influence of the anthropogenic aerosols over the site is relatively less due to higher elevation and remoteness from large industrial and population centers in the Ganges Valley region. Therefore, the study region has been suggested to be a regional representative site of aerosols and trace species measured in the northern part of India 
(Sarangi et al., 2014). The highest surface temperature $\left(\sim 30^{\circ} \mathrm{C}\right)$ is observed during pre-monsoon and the lowest $\left(-1^{\circ} \mathrm{C}\right)$ is observed in winter season. The wind patterns during winter and summer seasons are northwesterly and southwesterly respectively. The detailed description of the general meteorology and topography of the observational site can be found in Shukla et al. (2014) and Sarangi et al. (2014).

\section{Observations and Methodology}

\subsection{Doppler Lidar}

During the GVAX campaign, various ground based in-situ as well as remote sensing instruments were deployed at the Manora Peak, Nainital site to measure different atmospheric parameters. The vertical profiles of the vertical wind velocity, horizontal winds and attenuated aerosol backscatter were obtained using coherent Doppler Lidar (DL). The technical and operational details of DL are discussed in Pearson et al. (2009) and Newsom (2012). DL scans the atmosphere in three different scanning modes viz. vertically pointing beam or fixed beam stare (FPT), range height indicator (RHI) (scans performed by sweeping the elevation angle while holding the azimuth angle fixed) and plan-position indicator scan (PPI) (scans performed by sweeping the azimuth angle while holding the elevation angle fixed).The mixing layer height was estimated by applying the wavelet co-variance transform (WCT) method on the vertical velocity variance $\left(\mathrm{m}^{-2} \mathrm{~s}^{-2}\right)$ data. A detailed description of the WCT can be found in Shukla et al. (2014).

\subsection{Multi Filter Rotating Shadow band Radiometer (MFRSR)}

For the present study, we have estimated AOD from Multi Filter Rotating Shadow band Radiometer (MFRSR) and the detailed description about the estimation method of AOD from MFRSR has been given by Harrison and Michalsky (1994). To examine the presence of 
convectively generated GWs in the AOD, we used the AOD at $0.5 \mu \mathrm{m}$ during $9.5-15.5 \mathrm{LT}$ on 19 October 2011 as shown in figure 2(a). Diurnal variation of aerosol radiative forcing (ARF) estimations over the observational site is done by giving the optical properties of aerosols as an input to the Santa Barbara DISORT Radiative Transfer (SBDART) model (see Ricchiazzi et al., 1998).

\section{Results and discussion}

In order to visualize the diurnal pattern of ABL at Manora Peak, height-time vertical velocity (VV) variation is plotted on 19 October 2011 as shown in Figure 1a. The black dotted line shows the mixing layer height (MLH) on 19 October 2011. It is clearly observed that during daytime intense solar radiation and strong convection, leads to maximum positive velocities (upslope wind) as high as $\sim 2 \mathrm{~ms}^{-1}$. While, negative velocities (downslope wind) are dominant during nighttime since surface cools (air mass descends) in the absence of solar radiation. The observed daytime upslope winds and nighttime downslope winds are also consistent with the previous weather research and forecasting (WRF) model based study over the Manora Peak (Sarangi et al., 2014).

The mean mixing layer height observed during daytime is $\sim 0.6 \pm 0.12 \mathrm{~km}$ above ground level (AGL) on 19 October 2011. It is interesting to note that the diurnal variation of MLH and vertical velocity (VV) both depict signatures of periodic oscillations. In this direction, VV and attenuated backscatter (Attb) data obtained during 9.5 - 15.5 LT on 19 October 2011 were investigated to evaluate the influence of wave modulations during daytime ABL evolution.

To see the aerosol concentration over the site observed by DL on 19 October 2011, we have plotted the diurnal variation of Attb during 9.5-15.5 LT as shown in Figure 1b. The observed Attb also showed increase during daytime and then a decrease during evening hours. It 
is also observed that Attb strength is maximum near boundary layer top because of maximum relative humidity $(\mathrm{RH})$ indicating hygroscopic nature of aerosols.

To examine the role of short-period modulations during daytime ABL evolution, we have performed Fourier analysis to VV time series data at different heights (Figure 1c). It is clearly noticed that $\sim 60-80$ min periodicities are dominant during daytime in VV data and these modulations seem to be amplified reaching maximum at the mixing layer height $(\sim 0.6 \mathrm{~km})$ and thereafter seem to be fading out in the free troposphere. To obtain the vertical phase propagation of short period modulations, we have applied band-pass filter of 60-80 min in the time series data of VV as a function of height (Figure 1d). It is interesting to note that filtered amplitudes are showing the upward propagation reaching maximum at $\sim 1 \mathrm{~km}$ with maximum amplitude at 14 LT in the afternoon. However, modulations slowly fade after 14 LT due to surface cooling.

To further understand the daytime ABL dynamics and convective processes originating in the nearby valley region to the site, we have taken range height indicator (RHI) snapshots of average radial velocity for morning hours (before noon) and afternoon hours separately on 19 October 2011 (Figure 1e-f), respectively. It should be noted that this type of representation is useful in understanding how the pollutants are transported from the nearby valley regions to the elevated site. The ground range $( \pm 1.5 \mathrm{~km})$ is the distance from the DL to a given sample point (valley region on both sides of our site) and the origin is the instrument location. A strong signal is observed in near vertical direction and at higher elevation angles which can be understood in terms of the valley region dynamics over the site. Strong upslope wind is clearly evident immediately after sunrise when surface heating starts dominating and the pollutants from the nearby valley region are uplifted by convective mixing and upslope wind over the site. The strong convective activity during afternoon hours shows the presence of thermals during the 
daytime and could be the plausible reason for the convectively generated upward propagating short-period modulations over the site. However, during the evening hours and due to decreasing surface heating the mixing fades away and the aerosols are contained within the surrounding valley due to dominant down slope winds.

To further observe the signatures of short-period modulations in AOD, we have utilized MFRSR data at $0.5 \mu \mathrm{m}$ during 9.5-15.5 LT on 19 October 2011 over the site. Figure 2a shows the time evolution of AOD during the daytime and shows an average value of $\sim 0.21 \pm 0.01$ during the observational time period (9.5-15.5 LT). An increasing trend is clearly visible in AOD and the enhancement is pronounced in the afternoon $(\sim 12 \mathrm{LT})$ and especially in late afternoon hours. This shows the importance of the daytime ABL dynamics and wind patterns in aerosol transport over the Himalayan region and potentially to the higher elevations. Spectral analysis is performed on AOD time series data to extract dominant periodicities as depicted in Figure $2 \mathrm{~b}$. The dominant 60-80 min periodicities with $95 \%$ significance level are seen from Figure $2 \mathrm{~b}$. Interestingly, similar periodicities are also observed in the time series of DL VV data during the observational period. The observed modulations in both the parameters signify the role of convection in modulating the AOD, leading to the transport of aerosols from lower altitudes to higher altitudes over the site. In order to see the time evolution of these periodicities, we have used Morlet wavelet transform (for details, Torrence and Compo, 1998) in the present study. Figure 2(c) shows the wavelet power spectrum of AOD. Dominant 60-80 min modulations are clearly evident in the later part of the data, implying that these modulations may be associated with an increase of AOD in afternoon hours (12 LT). Nevertheless, dissipation of these oscillations is observed in the absence of surface heating/convection process. 
Now, we calculate the contribution of the short-period modulations in diurnal variation of aerosol radiative forcing (ARF) over the site. Instantaneous optical properties of aerosols were estimated by OPAC model based on the aerosol optical depth at different wavelengths (MFRSR) and black carbon mass concentration (Aethalometer) measurements. These properties have been used in SBDART model for the estimation of ARF. Details about the methodology of ARF estimation by using SBDART model can be found in Reddy et al. (2015). Atmospheric forcing (AF) which generally represents the total energy trapped by the atmosphere is estimated by taking the difference between top of the atmosphere (TOA) and the surface ARF (Kumar et al., 2011). Figure 3 shows the diurnal variation of ARF at the surface, Top of the Atmosphere (TOA) and atmospheric forcing due to aerosols for mean (M) AOD and also inclusion of wave amplitude with mean AOD (mean (M) AOD + wave amplitude (W)) on 19 October 2011. The positive and negative value of $\mathrm{ARF}$, in general represents the heating and cooling in the atmosphere respectively. It is clearly evident that the surface (TOA) aerosol radiative forcing values are decreasing/increasing during daytime and the maximum is observed at $13 \mathrm{LT}$ indicating that the high AOD over the site is due to convection and upslope wind flow. The mean (9.5-15.5 LT) aerosol radiative forcing of $\mathrm{M}(\mathrm{M}+\mathrm{W})$ are given in Table 1. It is interesting to note that wave amplitude increases during daytime and has maximum amplitude at 14 LT and quickly dissipates and reaches a minimum in the evening hours.

Earlier reports from various locations showed the short-period modulations in the stable nocturnal boundary layer (Devara et al. 1994; Manoj and Devara 2011, Gibert et al. 2011). Gibert et al. (2011) investigated different case studies about the generation mechanism of the gravity waves (GWs) in wind component of $A B L$ in the morning transition. They suggested that the waves are partially trapped in ABL. However, there are limited studies discussing the 
relationship between short-period modulations and dynamics over this region (Manoj and Devara, 2011; Das et al., 2011). Earlier, Phanikumar et al. (2014) investigated the effect of longperiod modulations on ARF and found an additional warming $\left(\sim 4 \mathrm{Wm}^{-2}\right)$ in the atmosphere due to insertion of wave amplitude in ARF estimations over the central Himalayan region.

\section{Summary and concluding remarks}

The diurnal pattern of ABL over the foothills of the Himalayan region does not vary significantly and mean mixing layer height is $\sim 0.6 \pm 0.12 \mathrm{~km}$ during the daytime. In the afternoon, temperature gradient provides an upwelling motion to the pollutants including aerosols from the nearby valley region to higher altitudes. It should be noted that our observations showed for the first time the dominant periodicities $(60-80 \mathrm{~min})$ through vertical velocity data, and also reconfirmed that these oscillations are evident in AOD time series data. It is surmised that the short-period modulations during daytime play a critical role in modulating AOD thereby affecting forenoon-afternoon asymmetry in AOD over the site. In addition, present analysis clearly showed that convective activity could trigger well defined short-period wave like oscillations that modulated/trapped aerosols. Our preliminary analysis suggests that inclusion of wave amplitude in the diurnal variation of ARF estimations showed during daytime an additional warming of $\sim 40 \%\left(15.5 \pm 2 \mathrm{Wm}^{-2}\right)$ in the atmosphere. It should be noted that the present analysis may not be sufficient to understand whether these aerosols are eventually transported and deposited on to higher elevations which have immense importance in wave induced aerosol dynamics over the central Himalayan region.

\section{Acknowledgments}


Ganges Valley Aerosol Experiment (GVAX) was a collaborative effort between the US Department of Energy Atmospheric Radiation Measurement Program, the Indian Institute of Science (IISC) and the Indian Space Research Organization (ISRO). We thank the Director of the Aryabhatta Research Institute of Observational Sciences (ARIES) for providing the necessary support.

\section{References}

Beegum, S. N., Krishna Moorthy, K., Babu, S. S., Reddy, R. R., and Gopal, K. R., 2009. Large scale modulations of spectral aerosol optical depths by atmospheric planetary waves, Geophys. Res. Lett., 36, L03810, doi: 10.1029/2008GL036509.

Browning, K. A., Wexler, R., 1968. The determination of kinematic properties of a wind field using Doppler lidar. J Appl Met 7:105-113

Das, S. K., Taori, A., Jayaraman, A., 2011. On the role of dust storms in triggering atmospheric gravity waves observed in the middle atmosphere. Ann Geophys 29:1647-1654.

Duchi ,R.,P. Cristofanelli, A. Marinoni , L. Bourcier, P. Laj , F. Calzolari ,B. Adhikary, G.P. Verza , E. Vuillermoz , P. Bonasoni,2014, Synoptic-scale dust transport events in the southern Himalaya, Aeolian Research 13 (2014) 51-57.

Dumka, U. C., Satheesh, S. K., Pant, P., Hegde, P., and Krishna Moorthy, K., 2006. Surface changes in solar irradiance due to aerosols over central Himalayas, Geophys. Res. Lett., 33, L20809, doi: 10.1029/2006GL027814.

Dumka, U. C., Krishna Moorthy, K., Satheesh, S. K., Sagar, R., and Pant, P., 2008. Short- period modulations in aerosol optical depths over the central Himalayas: role of mesoscale processes, J. Appl. Meteorol. Climatol., 47, 1467-1475, doi:10.1175/2007JAMC1638.1. 
a. Dumka, U.C. and Kaskaoutis D.G., 2014. In-situ measurements of aerosol properties and estimates of radiative forcing efficiency over Gangetic-Himalayan region during the GVAX field campaign, Atmospheric Environment, 94, 96-105.

b. Dumka et al, 2014, Seasonal inhomogeneity in cloud precursors over Gangetic Himalyan region during GVAX campaign, Atmospheric Research, 155,158-175.

Dumka U.C., Kaskaoutis D.G., Srivastava M.K. and Devara P.C.S.,2015, Scattering and absorption properties of near-surface aerosols over Gangetic-Himalyan region:the role of boundary layer dynamics and long-range transport, Atmos. Chem.Phys.,15,1555-1572.

Fritts, D. C., Alexander, M. J., 2003. Gravity wave dynamics and effects in the middle atmosphere. Reviews of Geophys 41: 1, DOI: 10.1029/2001RG000106

Gibert, F., Arnault, N., Cuesta, J., Plougonven, R., Flamant, P. H., 2011. Internal gravity waves convectively forced in the atmospheric residual layer during the morning transition. Q J R Meteorol Soc: DOI:10.1002/qj.836.

Gobbi, G. P., Angelini, F., Bonasoni, P., Verza, G. P., Marinoni, A., Barnaba, F., 2010. Sunphotometry of the 2006-2007 aerosol optical/radiative properties at the Himalayan Nepal Climate Observatory- Pyramid (5079ma.s.1.). Atmos Chem Phys Discuss 10:1193-1220, doi: 10.5194/acpd-10-1193-2010

Harrison, L., Michalsky, J., 1994. Objective algorithms for the retrieval of optical depths from ground-based measurements. Appl Opt 33:5126-5132.

Jethva, H., Satheesh, S. K., Srinivasan, J., 2005. Seasonal variability of aerosols over the IndoGangetic basin. J Geophys Res 110: D21204 doi: 10.1029/2005JD005938 
Komppula, M., Lihavainen, H., Hyvärinen, A.-P., Kerminen, V.-M., Panwar, T. S., Sharma, V. P., Viisanen, Y., 2009. Physical properties of aerosol particles at a Himalayan background site in India, J Geophys Res, 114: D12202 doi: 10.1029/2008JD011007.

Kotamarthi V.R., 2010, Ganges Valley Aerosol Experiment: Science and Operations Plan, DOE/SC-ARM-10-019.

Kumar R, Naja M, Venkataramani S, Wild O, 2010, Variations in surface ozone at Nainital: a high altitude site in the central Himalayas. J. Geophys. Res., 115:D16302.

Kumar R., Naja M., Satheesh S.K., Ojha N., Joshi H., Sarangi T., Pant P., Dumka U.C., Hegde , and Venkataramani S., 2011. Influences of the springtime northern Indian biomass burning over the central Himalayas. Journal of geophysical research, vol. 116, D19302, 14 PP., 2011, doi: 10.1029/2010JD015509.

Manoj, M. G., Devara, P. C. S., 2011. Quasi-periodic oscillations of aerosol backscatter profiles 245 and surface meteorological parameters during winter nights over a tropical station, Ann Geophys 29:455-465

Manoharan V.S., Kotamarthi, R., Feng,Y. and Cadeddu M.P., 2014, Incraesed absorption by coarse aerosol particles over the Gangetic-Himalyan region, Atmos. Chem.Phys.,14,1159-1165.

Nappo, C. J., 2002. An introduction to atmospheric gravity waves. International geophysics series, vol 85. Academic, London, 276 pp.

Newsom, R. K., 2012. Doppler Lidar (DL) Handbook, DOE/SC-ARM-TR-101. www.arm.gov/publications/tech_reports/handbooks/dl_handbook.pdf.

Niranjan Kumar, K., Ramkumar, T. K., Krishnaiah, M., 2012. Analysis of large-amplitude stratospheric mountain wave event observed from the AIRS and MLS sounders over the western Himalayan region, J. Geophys. Res., 117, D22102, doi: 10.1029/2011JD017410. 
Niranjan Kumar, K., Rao, Ch. K., Sandeep, A., Rao, T. N., 2014. SODAR observations of inertia-gravity waves in the atmospheric boundary layer during the passage of tropical cyclone, Atmos Sci Lett, DOI: 10.1002/asl2.478.

Ojha N., M. Naja, K. P. Singh, T. Sarangi, R. Kumar, S. Lal, M. G. Lawrence, T. M. Butler, and H. C. Chandola.,2012,Variabilities in ozone at a semi-urban site in the Indo-Gangetic Plain region: Association with the meteorology and regional processes, J. Geophys. Res., 117, D20301, doi: 10.1029/2012JD017716.

Phanikumar, D. V., Niranjan Kumar, K., Shukla, K. K., Joshi, H., Venkat Ratnam, M., Naja, M., and Reddy, K., 2014. Signatures of Rossby wave modulations in aerosol optical depth over the central Himalayan region. Ann Geophys 32:175-180.

Pearson, G.N., Davies, F., Collier, C., 2009. An analysis of the performance of the UFAM pulsed Doppler lidar for observing the boundary layer. J Atmos Oceanic Technol 26:240-250

Ramkumar, T. K., Niranjan Kumar, K., Mehta, S. K., 2010. Mesosphere-stratospheretroposphere radar observations of characteristics of lower atmospheric high-frequency gravity waves passing through the tropical easterly jet, J. Geophys. Res., 115, D24109, doi: 10.1029/2009JD013733.

Reddy, K., Phanikumar, D.V., Joshi, H., Ahammed, Y. N., Naja, M., 2015. Effect of diurnal variation of aerosols on surface reaching solar radiation, J Atmos Solar-Terrestrial Phys, 129: 62-68, dx.doi.org/10.1016/j.jastp.2015.04.011.

Ricchiazzi, P., Yang, S., Gautier, C., Sowle, D., 1998. SBDART: A research and teaching software for plane-parallel radiative transfer in the earth's atmosphere. Bull Am Meteorol Soc, 79, 2101-2114. 
Sagar, R., Kumar, B., Dumka, U.C., Moorthy, K.K., Pant, P., 2004. Characteristics of aerosol optical depths over Manora Peak: A high altitude station in the central Himalayas. J Geophys Res 109:D06207, doi: 10.1029/2003JD003954

Sarangi, T., Naja, M., Ojha, N., Kumar, R., Lal, S., Venkataramani, S., Kumar, A., Sagar, R., Chandola, H.C., 2014. First simultaneous measurements of ozone, CO and NOy at a high altitude regional representative site in the central Himalayas, J. Geophys. Res. 119(3), 1592-1611.

Shukla, K. K., Phanikumar, D. V., Newsom, R. K., Niranjan Kumar, K., Venkat Ratnam, M., Naja, M., Singh, N., 2014. Estimation of the mixing layer height over a high altitude site in Central Himalayan region by using Doppler lidar. J Atmos Solar-Terrestrial Phys, 109:48-53.

Stull, R. B., 1988. An Introduction to Boundary Layer Meteorology, Kluwer Academic Publishers, Dordrecht, Germany.

Torrence, C., Compo, G.P., 1998. A practical guide to wavelet analysis, B Am Meteorol Soc, 79, 61-78, doi: 10.1175/1520- 0477(1998)079<0061: APGTWA>2.0.CO; 2.

\section{Figure Captions}

Figure 1: (a) Height-time variation of vertical velocity observed by Doppler Lidar during 9.515.5 LT and dotted black line represents the mixing layer height (MLH) during same period (b) Height-time variation of attenuated backscatter observed by Doppler Lidar during 9.5-15.5 LT (c) Fourier spectrum of vertical velocity observed by Doppler Lidar during 9.5-15.5 hr (d) Band pass filtered (60-80 min) amplitude of vertical velocity (e) Doppler Lidar range-height indicator scan snapshots during (e) morning hours and (f) afternoon hours during 19 October 2011. 
Figure 2: (a) Temporal variation of aerosol optical depth (AOD) during 9.5-15.5 LT, (b) Fourier transform normalised power varaition with period and(c) Wavelet power spectra of AOD during 9.5-15.5 LT during 19 October 2011. The contour represents the 95\% confidence level.

Figure 3: Temporal variation of aerosol radiative forcing (ARF) at the top of atmosphere (TOA),surface and atmosphere during 6.5-17.5 LT on 19 October 2011.

Table 1: Amplitude of aerosol radiative forcing (ARF) with mean AOD and with inclusion of gravity wave amplitude at top of the atmosphere (TOA), surface and atmosphere.

\begin{tabular}{|l|c|c|}
\hline \multicolumn{1}{|c|}{$\begin{array}{c}\text { Aerosol Radiative } \\
\text { Forcing }\end{array}$} & $\begin{array}{c}\text { Forcing with mean AOD } \\
\left(\mathbf{W . m ^ { - 2 } )}\right.\end{array}$ & $\begin{array}{c}\text { Forcing with mean AOD + } \\
\text { wave amplitude } \\
\left(\mathbf{W} \cdot \mathbf{m}^{-2}\right)\end{array}$ \\
\hline $\begin{array}{l}\text { Top of the atmosphere } \\
\text { (TOA) }\end{array}$ & 1.25 & 2.42 \\
\hline $\begin{array}{l}\text { Atmospheric forcing } \\
\text { (TOA-Surface) }\end{array}$ & 34.85 & 50.19 \\
\hline Surface & -33.60 & -47.78 \\
\hline
\end{tabular}



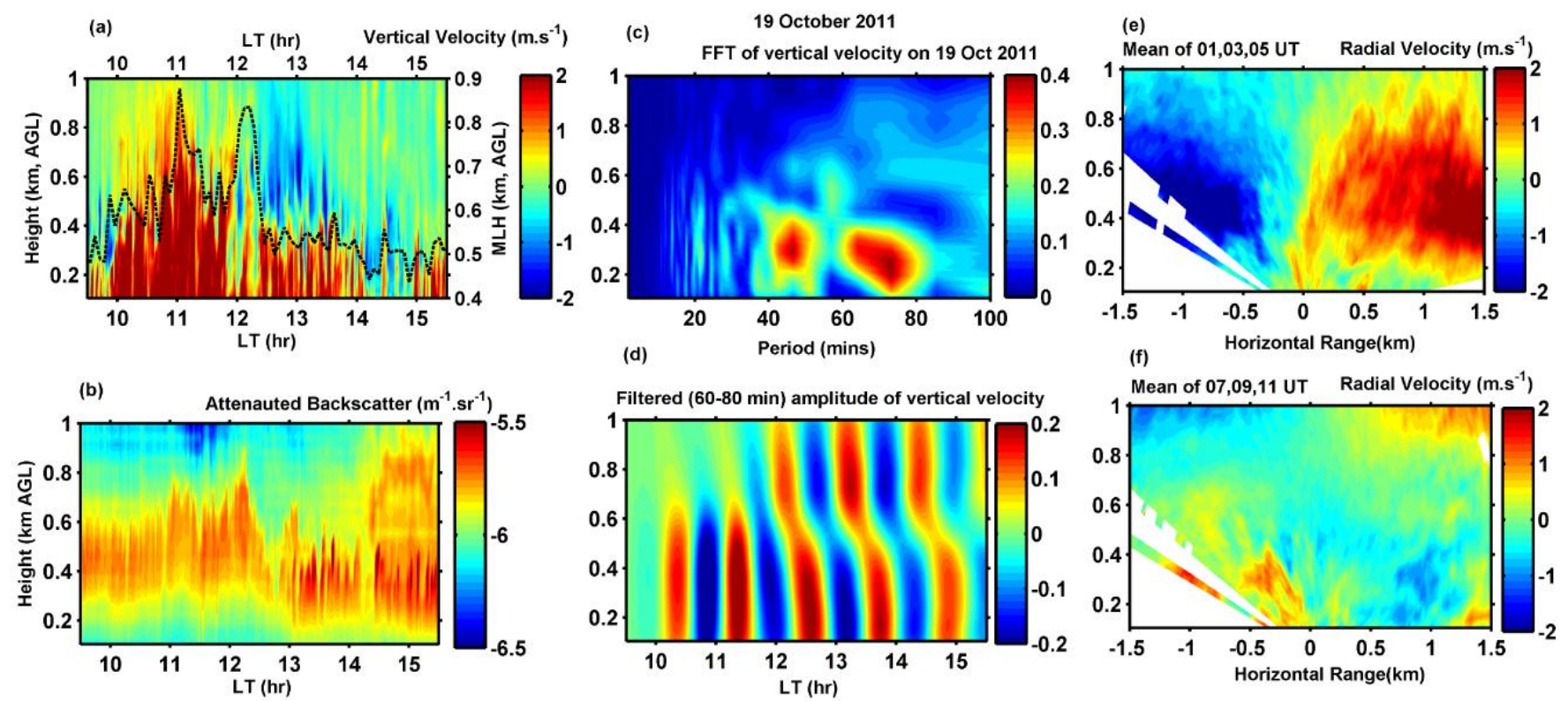
Figure 2

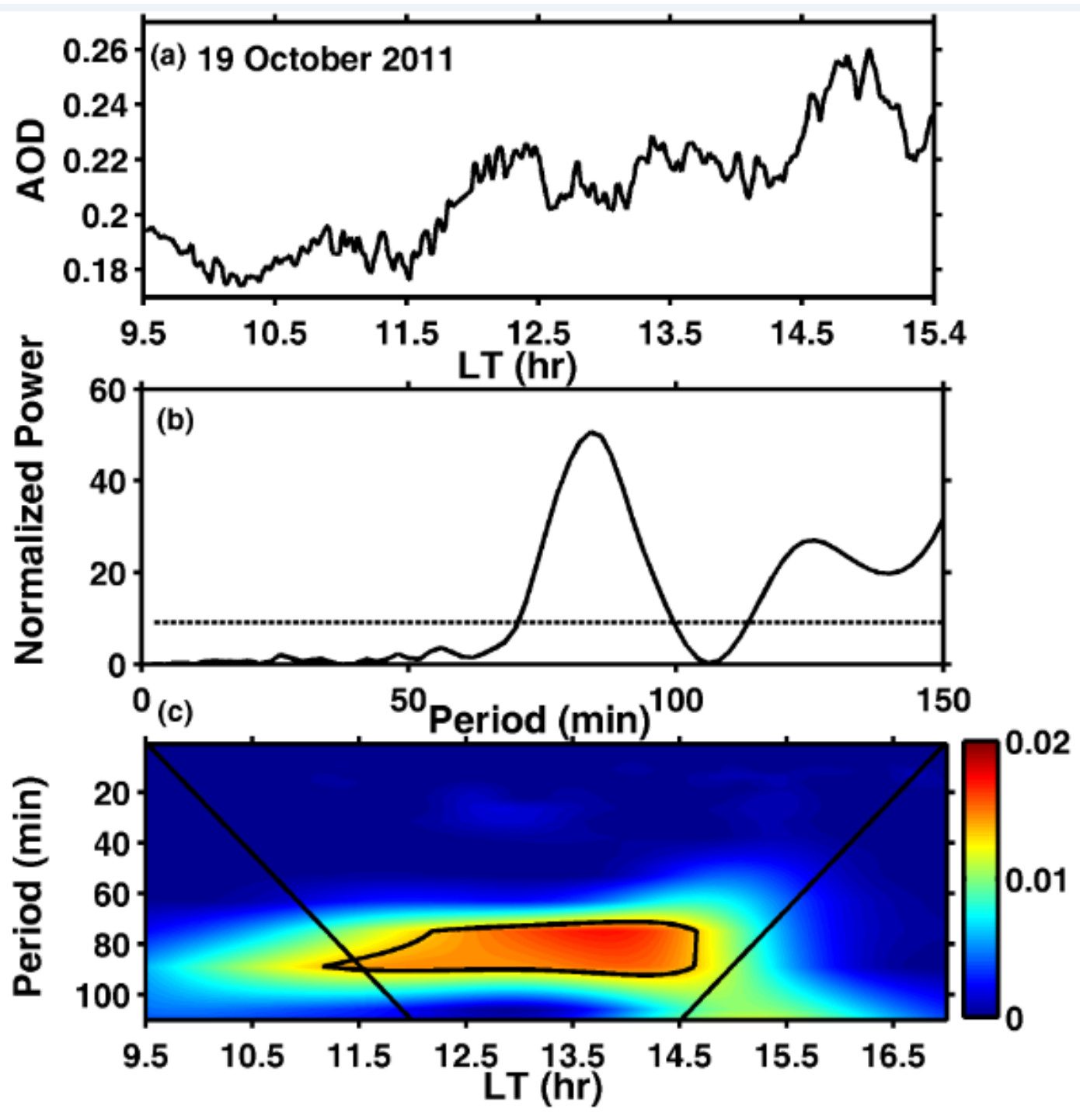


Figure 3

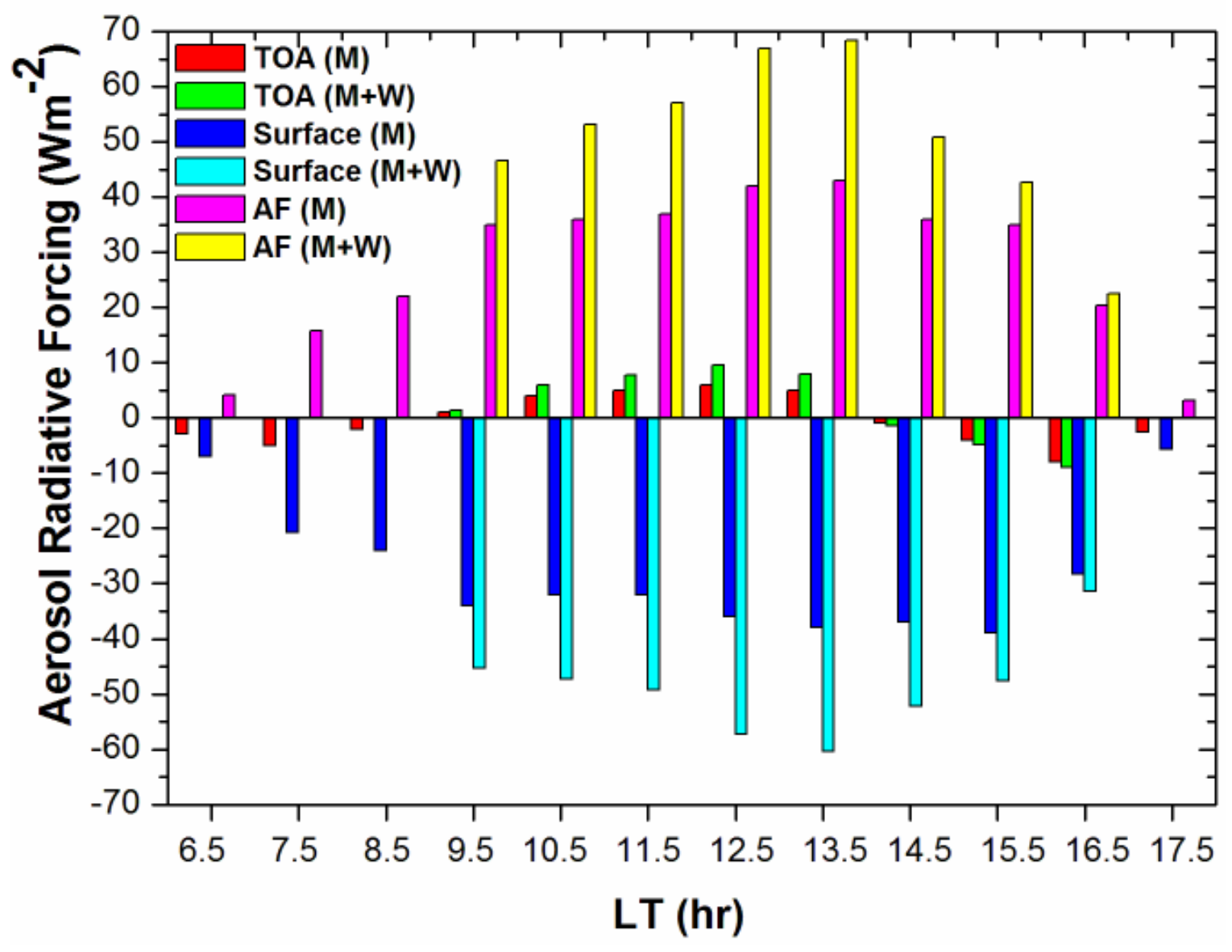

47

48

49

50

51

52

53

54

55

56

57

58

59

60

61

62

63 